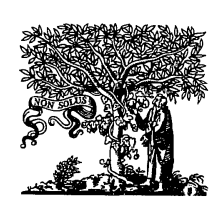

ELSEVIER
International Journal of Risk \& Safety in Medicine $7(1995) \mathrm{v}-\mathrm{vi}$

\title{
Editorial
}

\section{Obesity: taking safety seriously}

It is sufficiently clear today, at least to anyone who has followed the literature (including any reasonably informed lay person), that obesity is a medical disorder. A condition which society has at various times regarded primarily as a cosmetic virtue, a cosmetic disaster, a source of humour or a mere physical inconvenience is very clearly pathological in its consequences and commonly also in its causes. Like any other disorder it needs to be treated - sympathetically, wisely and safely.

The trouble, even today, is that the old attitudes to obesity have left their mark. Sympathy for the obese individual who is truly anxious to reduce weight, but finds difficulty in doing so, is not always in evidence; surely, goes the simplistic thinking, if he or she were just sensible enough to eat rather less the problem would be solved? The wisdom of various forms of treatment is at least dubious; a proper diagnosis is not very often made, and without even an attempt to find the aetiology there is not a great deal of hope of success in therapy. As to safety: neither drugs nor surgery have a clean record; it is not very long ago that dinitrophenol, thyroxine and amphetamines were freely available across much of Europe, and in parts of the world they still are.

The doctor may be misguided in his approach to obesity; the sufferer is at least as likely to be on the wrong track. It is very tempting to resort to the notorious crash diet, starving oneself drastically for a period of time until the inevitable moment comes when the pendulum swings back and one ends up at least as obese as before; the adventure has been neither effective nor healthy. The obese lay person is also less likely to be led than misled when looking for some means to make the process of weight reduction less burdensome. Fatness has long been a favourite hunting ground for the seller of remedies which are at least worthless and at most dangerous, and the weekly magazines with their constant revelations of new dietary cures devised by the famous and foolish have hardly helped matters. 
For all those reasons, it is tremendously encouraging to see a group of lay people who have struggled with the obesity problem taking the initiative themselves to help one another. That has long been happening on the small scale, with group meetings and informal courses. It happened on the grand scale late in 1993 in Antwerp, when a pioneering organization known as "Obesitas" called a very well devised congress of experts to hammer out the entire problem: what do we know, and what do we not know, about the proper diagnosis and safe treatment of obesity? Some of the leading papers from that meeting are presented in the present issue of the Journal.

This was not a meeting which raised hopes of some simple, all embracing cure just around the corner; it was sufficiently sensible to consider the need for an individual approach to the individual sufferer; it was very level-headed about claims for liposuction, appetite depression and fat-mobilizing hormones. The great thing about Antwerp was that the sympathy and the wisdom were both there: well-documented success stories were taken very largely as possible sources of inspiration for treating the individual properly, rather than being allowed to spark off any belief that the ultimate answer to obesity had emerged. The medical men and the surgeons, several of whom had their own very particular ideas on the matter, were kept well in hand by the sobriety of the organizers. It was an excellent start, and one which deserves to be emulated both on the large and small scale - perhaps also for conditions other than obesity. What about a congress on mental health where the patients similarly invite the doctors? A meeting on sports medicine, run by thinking sportsmen? There are plenty of conditions where we need to adjust the balance between the profession and the patient; and this is one very promising way to do it.

Graham Dukes 